\title{
Commentary
}

\section{\#NewWSUnites: Reflections on institutionalising acceptance and diversity through Sydney's Gay and Lesbian Mardi Gras Parade}

\author{
Tinashe Dune \\ Western Sydney University \\ Ann Cheryl Armstrong \\ Western Sydney University
}

Keywords: institutionalising acceptance, policy and advocacy, sexual orientation, gender identity, LGBTIQ, mental health, wellbeing

The institutionalisation of discrimination is often cited as a key factor in poor health and wellbeing outcomes for people identifying as lesbian, gay, bisexual, transgender, intersex and queer (LGBTIQ). Such health outcomes include poor mental health, psychological stress resulting in physical manifestations of illness, and higher incidence of drug and alcohol abuse, in addition to higher prevalence of self-harm and suicide (Jones, del Pozo De Bolger, Dune, Lykins \& Hawkins, 2015). McNair and Hughes (2012) also cite a higher prevalence of risk factors for cardiovascular disease and cancer, and lower rates of preventive screening, which all contribute to poor health outcomes. However, institutionalisation of LGBTIQ acceptance is also on the rise (Ellis, 2009; Renn, 2007). This is especially the case within higher education institutions, with many people around the world leading awe-inspiring initiatives to celebrate diversity. For instance, through the It Gets Better campaign (2015) many universities have incorporated the acceptance of diversity as part of their institutional and public image. Considering that such organisations are often in positions of both privilege and influence, they are well placed to champion change within their communities.

In addition to groups that function within universities to support the institutionalisation of diversity, a few of Australia's universities participate in the annual Sydney Gay and Lesbian Mardi Gras Parade. These groups include Ally Networks (groups of staff) and Queer Collectives (groups of students), committed to creating an inclusive and respectful culture at their university for LGBTIQ community members. In recognition of this prime opportunity to publically demonstrate the importance of diversity (instead of simply having it stated in policy documents, as per Ellis, 2009), Western Sydney University (in conjunction with its Ally Network and Queer Collective) collaborated to prepare and deliver a float for the University's first appearance in the Parade (see Figure 1).

\section{The parade, the university and the region}

The Sydney Gay and Lesbian Mardi Gras had its genesis in June 24 1978, as a protest march and commemoration of the Stonewall Riots that took place at the Stonewall Inn in New York's Greenwich Village. The annual parade "has become an all-encompassing expression of LGBTQI identity" which was initiated through a single night of protest about prejudice and discrimination (Sydney Gay \& Lesbian Mardi Gras, 2015). Forged from the pursuance of liberty, the parade also commemorates "an overarching sense of love and a joyous celebration of the hard won freedom to be whoever you are" (Sydney Gay \& Lesbian Mardi Gras, 2015). As co-organisers of the Western Sydney University float, it became clear that institutionalising this acceptance of diversity is fundamentally rewarding but was sometimes challenging. As such, this commentary presents some reflections on working to embed the acceptance of diversity in an institutional culture.

Corresponding author: Tinashe Dune (t.dune@westernsydney.edu.au) 


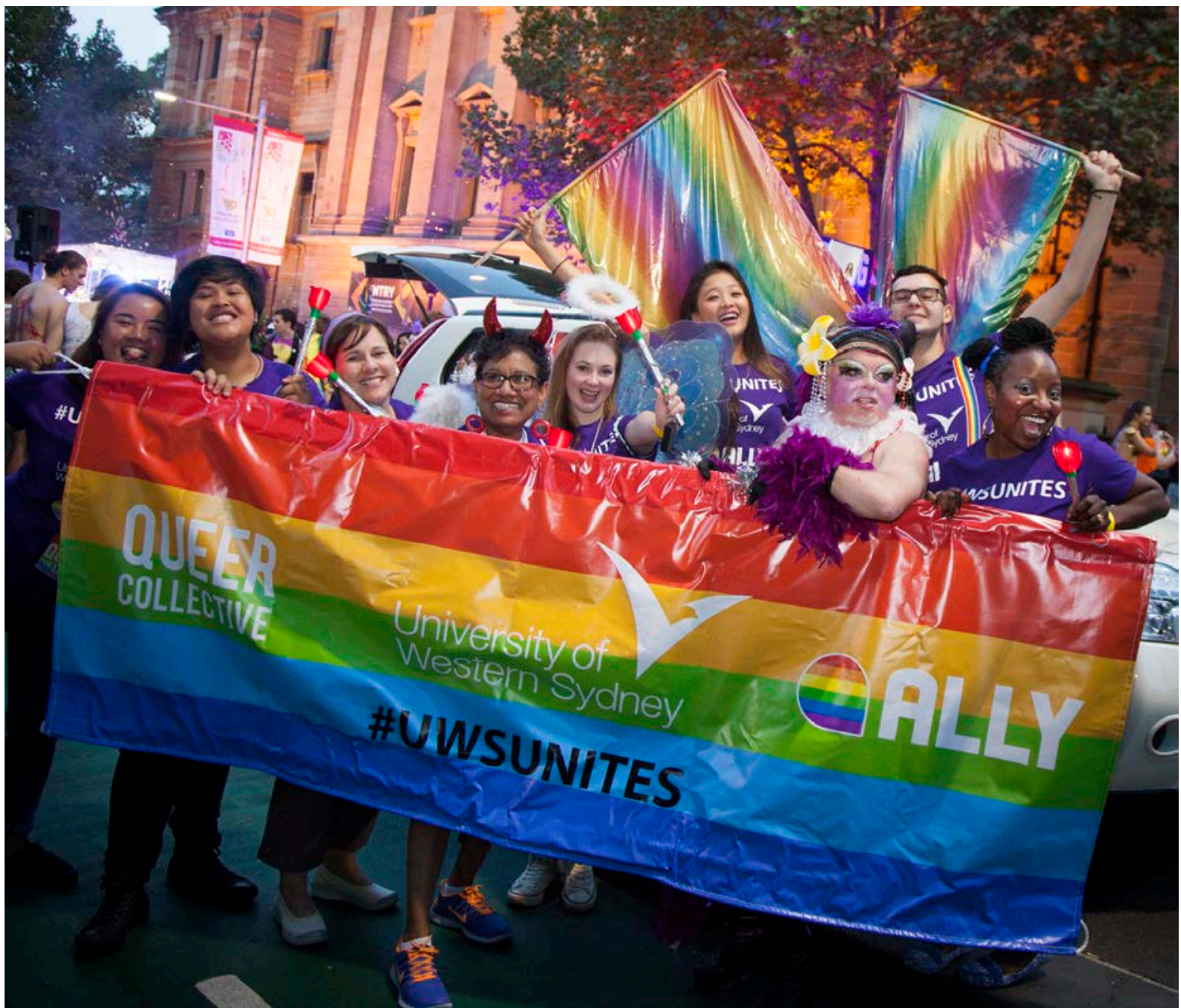

Figure 1: \#NewWSunites Mardi Gras 2015 Float \& Marchers

Western Sydney University is situated within the demographically diverse Greater Western Sydney region. It has a rapidly expanding population, which is expected to continue to rise by a further 51\% over the next 15 years to 2.5 million (Parliament of New South Wales, 2012). In the most recent census, Greater Western Sydney (compared with Central and Inner City Sydney) included a comparatively high number of people from culturally and linguistically diverse backgrounds (approx. 800,000). Many are of Aboriginal and Torres Strait Islander heritage (approx. 4,500 people), and are categorised as coming from low socioeconomic backgrounds (Australian Bureau of Statistics, 2011). Greater Western Sydney is also home to an increasing number of residents who identify as LGBTIQ (Besanvalle, 2011). Embedded within its mission of Making the Difference and Securing Success, the university is known for its cultural diversity, commitment to inclusion and community engagement. Given the diversity of the region, it became apparent that the university had a prime opportunity show its support for the LGBTIQ community in both the university and the wider Western Sydney region.

Although there are many forums through which the university could, and does, demonstrate its commitment to acceptance and inclusion, its presence at the Sydney Gay and Lesbian Mardi Gras Parade is an action-based acknowledgement of the role institutions play in the social, political and cultural acceptance of sexual diversity. This year the parade included over 10,000 participants and 140 floats, attracting over 300,000 spectators from Australia and overseas. Considering the reach of the parade, the university's participation is impactful not only in the Western Sydney region but also has far reaching effect nationally and 
globally. Of the five major aims of the Sydney Gay and Lesbian Mardi Gras Parade, the university's inclusion in the event speaks most significantly to the following:

1. providing the opportunity for LGBTIQ individuals and groups to use the Sydney Gay and Lesbian Mardi Gras as a statement of pride and to promote a broader message of diversity, acceptance and wellbeing

2. embracing individuals and groups from the broader community who share our vision for inclusion and acceptance.

\title{
The role of the parade towards institutionalising LGBTIQ acceptance
}

According to Hatzenbuehler (2014), support from institutions through open and transparent acknowledgment and acceptance of sexual diversity is imperative to prevent health problems linked with experiences of sexuality-based prejudice and discrimination towards LGBTIQ people. According to McNair and Hughes (2012), events like the parade highlight the importance of much-needed social, political and cultural changes in light of systems, leaders and services, which continue to discriminate against LGBTIQ identifying Australians. Further, they indicate that events like the parade become an explicit show of support, challenging workplace discrimination and acting as visible signs that one's organisation "wishes to help reverse health inequalities and create a safer society for LGBTI people" (McNaire \& Hughes, 2012, p. 224).

Questions may arise within organisations about the ways in which they could institutionalise acceptance of diversity. Firstly, there must be on-going reform underpinned by the political will exhibited by the senior management team to support diversity. Such a stance would enable diversity groups such as LGBTIQ to flourish within a safe, non-discriminatory and harassment free environment. It has been found that "homophobic comments from more senior staff make it more acceptable for junior staff to engage in such practices" (Bowers, Plummer, McCann, McConaghy \& Irwin, 2006, p. 112). For example, having recognised the successful effort made by Western's Ally Network to participate in Mardi Gras 2015, the Vice Chancellor of the University offered his patronage by sending an email to all staff encouraging them to be involved in preparing and marching for Mardi Gras 2016:

\begin{abstract}
Western's Ally Network and I are proud to announce that the University will build on this success by marching again in the 2016 Mardi Gras. Participating in this type of event is an important way to acknowledge, support and celebrate our staff, students and alumni from the Lesbian, Gay, Bisexual, Transgender, Intersex and Queer (LGBTIQ) community and their valuable contribution to the diversity of our University (All staff email by Glover, 2015).
\end{abstract}

This email also reinforced the Western's Ally Network's commitment to institutionalizing acceptance through staff involvement, by offering all staff involved in Mardi Gras 2016 preparations (up to seven hours of leave to use at their discretion). This simple act not only improves the visibility of LGBTIQ people and those who support them, but reinforces an over-arching principle that there is no place for prejudice and discrimination in our community, irrespective of gender or sexuality. Universities are an ideal platform for this message.

\section{Organisational systems and means for change}

Sometimes discrimination occurs not just by what someone says or the way others respond to issues but by systems, procedures and even forms which are convoluted and obstructionist rather than constructive and supportive. As Ainscow (2005) argues "strategies for developing inclusive practices have to involve interruptions to thinking in order to encourage an exploration of overlooked possibilities for moving practice forward" (p. 109). When instituting policies of diversity, staff responsible within the institution should engage with the various interest groups and request suggestions for improvement. This is a process that requires a commitment to have an on-going search to find better ways of responding, engaging and learning to value differences within our society but more importantly learning 
from the differences that occur. Organisations are better able to understand where they rank on LGBTIQ inclusion from a comprehensive self-assessment using criterion developed by The Rainbow Tick (Rainbow Tick Standards, 2013). Such a process can be facilitated by organisations like Pride in Diversity who developed The Australian Workplace Equality Index (2015), which has been described as:

the definitive national benchmark on LGBTI workplace inclusion and comprises the largest and only national employee survey designed to gauge the overall impact of inclusion initiatives on organisational culture as well as identifying and non-identifying employees. The Index drives best practice in Australia and sets a comparative benchmark for Australian employers across all sectors (para. 1).

Practical tools and action plans with measurable targets and timelines developed by liaising with these facilitative organisations, can ensure that progress is planned, made, measured and reported on. For Australian universities engaging with such a process is paramount to fulfilling their role as a means to promote social cohesion. Failure to do so may result in poor ranking within the Australian LGBTI Uni Guide (2015), a publically available resource indicating "how well Australian universities cater to the needs of LGBTI students through things like inclusive policies, staff training, or providing information, resources and support for LGBTI students" (para 1).

\section{International successes}

An interesting example of institutionalising LGBTIQ acceptance hails from the UK, where Stonewall (2015), a gay rights charity and member of the Equality and Diversity Forum, is well known for its campaigning and lobbying on behalf of lesbians, gays, bisexual and transgender people. They have achieved much acceptance in the wider community and their Diversity Champions programme offers advice and support to over 650 organisations in the UK. In January 2005, they launched an Education for All campaign to address homophobia and homophobic bullying in schools. Since 2010, they have published an online guide which rates the environment within UK universities on a league table on how gay friendly they are so that prospective students could compare their university choices.

The Stonewall University Guide (Stonewall, 2015) contains criteria to encourage universities to make better provisions for students and promises that the guide will assist prospective students to choose a university that will welcome and support them in being themselves. The guide rates universities on whether they:

1. have policies against homophobic bullying

2. monitor GBLT students; provide consultation, welfare, information and resources

3. support specific students' societies and events

4. provide specific career advice

5. support a network group for staff who have identified as GBLT

6. engage with the wider community.

Underpinning Stonewall's policy framework is the development of positive self-esteem through opportunities for networking and building confidence. The intention is to support students in an environment that allows them to excel. Universities have a duty of care towards all their students and perhaps one day Australian institutions of learning could consider using a template similar to Stonewall's to actively foster supportive and healthy learning environments on a more encompassing scale.

\section{Lessons learned}

It is therefore important that an organisation's institutional culture is explicitly (re)designed to promote equality (and equity) and eliminate discrimination or, as Hatzenbuehler (2014) calls it, structural stigma - a process which is currently engaged in Western's Ally Network. More broadly, for universities, this means that their policies, hiring frameworks, teaching ideologies, research objectives, and community engagement strategies need to be aligned 
with principles of social justice (Jones \& Williams, 2015) if we are to contribute to the development of a wholesome and inclusive society. As such, there are several ways in which LGBTIQ issues can be interwoven into the fabric of universities. For example, the organisation should ensure that there are policies of non-discrimination and anti-bullying that are enforced along, with research projects that explore all types diversity, gender issues, and the impact of prejudice and discrimination on all facets of life. Units of study could be included in undergraduate and postgraduate curricula, which address LGBTIQ harassment and discrimination issues. There should also be improved access to information on diversity and inclusion where the groups responsible reflect on barriers to inclusion and develop and implement strategies to remove barriers on an ongoing basis to promote wholesome inclusionary practices (Bowers et al, 2006).

However, even for organisations whose primary objective is to be people-centred there are barriers which need to be mitigated. For instance, in order for Western Sydney University to engage in its public demonstration of LGBTIQ acceptance and inclusion at the parade, a significant amount of coordination was required within a short-time frame between individuals and University departments. However, this was a necessary step forward on the journey. In our case, a synchronized and non-obstructionist mentality was required between the Office of Equity and Diversity, the Ally Network, the Queer Collective, the Office of Media and Communications, the Office of the Vice-Chancellor, the Office of People and Culture, Campus Security, Campus Life, individual students and academics, as well as with external bodies such as the parade organisers who made concessions to accommodate the University's specific ways of managing events. Without this organised effort and joint goal of institutionalising acceptance the university would not have been able to participate in the Parade (see also Rumens \& Broomfield, 2012). Further, many organisations operate through a number bureaucratic processes (Allan, 2014). When working within a tight timeframe, as we did, organisational bureaucracy can be interpreted as insurmountable and this can easily halt a project for weeks or months. This logistical hurdle can only be overcome, if there is commitment and willingness from all involved to work through such issues to achieve a beneficial and forward-focused outcome.

Finally, in the pursuit of inclusion and the celebration of diversity and well-being, it is important not to be hindered by a lack of experience. For example, in our case, this was the first time the University participated in the parade. Organisations that regularly rely on how things have been done in the past in order to make decisions about the present and the future, may discourage opportunities for organisational innovation (Laforet, 2013) and the development of new methods of community engagement.

Although barriers exist to institutionalising the acceptance of diversity, the over-arching message is that it can be done. Small steps can have a marked impact and build organisational confidence to take a public stance against sexuality-based inequity. Although our group was functioning within a University setting while planning, organising and delivering our float, individuals (who may have been the Vice-Chancellor, departmental directors and managers of the campus monies) were committed to and took ownership of institutionalising acceptance. The community response on Facebook and Yammer was extremely positive and demonstrates that such a task is necessary, do-able and impactful. On Facebook one student exclaimed:

I was in the crowd and so pleased to see my University, where I study and work, represented in the parade. It was a very proud moment and so good to feel accepted in my workplace. Well done UWS Mardi Gras team!

The Hon Michael Kirby AC CMG agrees that having a presence in the 2015 Sydney Gay and Lesbian Mardi Gras Parade helps to "make the university a safe and welcoming place for LGBTIQ staff and students" (personal communication, 10 March 2015). 


\section{References}

Ainscow, M. (2005). Developing Inclusive Systems: What are the Levers for Change? Journal of Educational Change, 6, 109 - 124.

Allan, J. (2014). Why Australian universities are just not good enough. Quadrant, 58(3), 44.

Australian Bureau of Statistics (2011). Census 2011. Canberra: Australian Government.

Australian LGBTI Uni Guide (2015). Australian LGBTI Uni Guide. Retrieved from: http://lgbtiuniguide.org.au/

Stonewall (2015). The Stonewall University Guide. Retrieved from: www.gaybydegree.org.uk

Besanvalle, J. (2011). It's not so bad out west. Retrieved from: http://www.samesame.com.au/features/7727/Its-not-so-bad-out-west

Bowers, R., Plummer, D., McCann,P., McConaghy, C. \& Irwin, L. (2006). How We Manage Sexual and Gender Diversity in the Public Health System: A Research Report. Armidale: University of New England. Retrieved from: http://www.glhv.org.au/files/how_we_manage_sexual_diversity_nsw.pdf.

Ellis, S. J. (2009). Diversity and inclusivity at university: A survey of the experiences of lesbian, gay, bisexual and trans (LGBT) students in the UK. Higher Education, 57(6), 723-739.

Hatzenbuehler, M. L. (2014). Structural stigma and the health of lesbian, gay, and bisexual populations. Current Directions in Psychological Science, 23(2), 127-132.

It Gets Better Australia New Zealand (2015). It Gets Better Campaign. Retrieved from: www.itgetsbetter.org.au

Jones, M. \& Williams, M. L. (2015). Twenty years on: lesbian, gay and bisexual police officers' experiences of workplace discrimination in England and Wales. Policing and Society, 25(2), 188-211.

Jones, T., del Pozo De Bolger, A., Dune, T., Lykins, A. \& Hawkes, G. (2015). Female-toMale (FtM) Transgender People's Experiences in Australia: A National Study. Dordrecht/Cham: Springer.

Laforet, S. (2013). Innovation characteristics of young and old family-owned businesses. Journal of Small Business and Enterprise Development, 20(1), 204-224.

McNair, R. P., \& Hughes, T. L. (2012). Coming out: is the Mardi Gras still needed? The Medical Journal of Australia, 196(4), 224-225.

Parliament of New South Wales (2012). Western Sydney: An Economic Profile. Retrieved from:

https://www.parliament.nsw.gov.au/prod/parlment/publications.nsf/key/WesternSydne $\mathrm{y}$ :AnEconomicProfile

Renn, K. A. (2007). LGBT student leaders and queer activists: Identities of lesbian, gay, bisexual, transgender, and queer identified college student leaders and activists. Journal of College Student Development, 48(3), 311-330.

Rumens, N. \& Broomfield, J. (2012). Gay men in the police: Identity disclosure and management issues. Human Resource Management Journal, 22(3), 283-298.

Sydney Gay and Lesbian Mardi Gras (2015). About the Sydney Gay and Lesbian Mardi Gras Parade. Retrieved from: http://www.mardigras.org.au/homepage/about/

The Australian Workplace Equality Index (2015). Australian Workplace Equality Index (AWEI). Retrieved from: http://www. prideindiversity.com.au/awei/

The Rainbow Tick (2013). Rainbow Tick Standards. Retrieved from: https://www.qip.com.au/standards/rainbow-tick-standards/

Western Sydney University (2015). Ally Network. Retrieved from: http://www.uws.edu.au/equity_diversity/equity_and_diversity/ally_network 


\section{Biographical notes}

Dr Tinashe Dune is co-convenor of Western's Ally Network and a holds Bachelor of Arts (Honours) in Psychology from Carleton University, a Master of Public Health in Human Sexuality from the Institute for Advanced Study in Human Sexuality and a PhD in Behavioural and Social Science in Health from the University of Sydney. Dr Dune is a Lecturer in Interprofessional Health Science at the University of Western Sydney whose teaching, research and community engagement focus on marginalised populations and social determinants of health.

Dr Ann Cheryl Armstrong is currently the Director, Academic Year Optimisation at Western Sydney University contributing to the strategic planning activities of the university. She was formerly the Director, Division of Professional Learning at the University of Sydney leading a team who provided advanced professional learning for educators both in New South Wales and internationally. Dr Armstrong's experience includes considerable knowledge and understanding of inclusion, academic systems in diverse, multicultural communities and working in collaborative settings. 